\title{
The role of plant breeders' rights in an evolving peach and nectarine fresh fruit sector
}

AUTHOR:

Chiedza Tsvakirai' (D)

\section{AFFILIATION:}

'Department of Agricultural Economics and Extension, North-West University,

Mmabatho, South Africa

\section{CORRESPONDENCE TO: Chiedza Tsvakirai}

\section{EMAIL:}

chichitsvakirai@gmail.com

\section{DATES:}

Received: 07 Nov. 2016

Revised: 17 Jan. 2017

Accepted: 10 Apr. 2017

\section{KEYWORDS:}

breeding; technology adoption; research policy; plant improvement; plant intellectual property

\section{HOW TO CITE:}

Tsvakirai C. The role of plant breeders' rights in an evolving peach and nectarine fresh fruit sector. S Afr J Sci. 2017;113(7/8), Art. \#2016-0339, 6 pages. http://dx.doi.org/10.17159/ sajs.2017/20160339

\section{ARTICLE INCLUDES: \\ $\times$ Supplementary material \\ $\times$ Data set}

\section{FUNDING:}

Agricultural Research Council (South Africa); University of Pretoria (c) 2017. The Author(s). Published under a Creative Commons Attribution Licence.
The evolving impact of plant breeders' rights was investigated in a bid to provide a basis for understanding the complex relationship that exists between scientific, legislative and market matters that shape the peach and nectarine fresh fruit sector. The results show that there is complementarity among varietal legislation, deregularisation, international trade policies, market trends and research intensity. Plant varietal legislation is found to play a facilitative role in ensuring the growth in the sector which has evolved from merely facilitating access to better quality cultivars which were bred beyond South Africa's borders, to the provision of good quality germplasm that aids in the breeding of locally bred varieties which better meet the production needs of local farmers. The results of the analysis show that strengthened varietal legislation has contributed significantly to cultivar development, reduced varietal concentration, increased resource (land) utilisation and increased export revenue generation and market penetration. The study warns of the negative effects that widening the scope of the Plant Breeders' Rights Act would have on innovation and cultivar access by poor farmers. Because of the strong ties existing between innovation and $R \& D$ investment, the recommendation is for an increase in $R \& D$ investment in the local research institution.

\section{Significance:}

- Insights into the impact of legislation on the industry's growth and development are given.

- Empirical evidence related to the sector's performance of the innovation market is presented.

\section{Introduction}

There is a general consensus that technical innovation can aid in solving diverse challenges facing the agriculture sector. According to Nhemachena et al. ${ }^{1}$, integrated innovations in areas such as seeds, biotechnology, crop protection, grain storage and transport are critical in improving global agricultural productivity. Seed development, in particular, has been hailed as one area of great importance as the seed contains the genetic code which sets the potential frontline of the production quantity and quality of an agricultural industry. ${ }^{2}$ As seed or cultivar development also plays a pivotal role in ensuring global economic development ${ }^{3}$, it is necessary to promote the exchange of such technologies across country borders because such innovations require substantial investments over long time periods (10 to 15 years ${ }^{1}$ ) to yield returns. The development of Intellectual Property Rights (IPRs) for plant varieties, such as plant breeders' rights (PBRs), has been instrumental in providing a secure business environment which allows breeders to achieve recognition for their efforts and receive compensation for their investments, while promoting the exchange of plant material.

The provision of IPRs for plant varieties has been a bone of contention since the introduction of the rights to living organisms. ${ }^{4}$ There is a general notion that plant variety laws favour the interests of multinational cooperates that are involved in their development at the expense of the farmer and the consumer ${ }^{5}$, particularly in developing countries ${ }^{6}$. The mixed results that are reported on the impact of plant variety legislation continue to fuel heated debates on whether such legislation stimulates or discourages shared economic growth. Various reports in developing countries have shown that plant variety legislation has contributed to higher foreign direct investment; increased genetic diversity; increased production of varieties which produce higher yields with a better quality agricultural output which have improved food security; and facilitated the provision of varieties which promote the use of sustainable farming practices. ${ }^{1}$ These reports imply significantly large economic benefits. In contrast, other findings show that the presence of PBRs has deterred seed development and hindered the economic participation of small-scale farmers in developing countries and has, overall, left the developing community worse off., ${ }^{2,7}$ Some find little evidence showing the achievement of intended goals. ${ }^{8}$

For the global peach industry, the development of plant IPRs was followed by the commencement of 'The Golden Age of Peach Breeding' ${ }^{\prime}$ - an era in which milestones in breeding techniques and in the quality and quantity of research outputs were achieved. Not much has been documented of the effects of this controversial legislation on peach production. Thus, a myriad of questions remain unanswered. A few of these questions - which were investigated in this study using South Africa's dessert peaches and nectarines fresh fruit sector as a case study - are:

- Have the benefits of agricultural biotechnology proliferated globally ${ }^{10}$ ?

- Has the legislation which promotes varietal exchange made any impact on variety adoption and cultivar concentration?

- Have these developments affected market concentration and participation in global markets?

- Has the market-oriented PBR legislation been to the benefit or detriment of South Africa, and how can the legislation be amended in such a way that the research community can maximise its gains? 


\section{History of plant variety protection}

The initial idea of granting varietal ownership largely came about as a result of the need for accountability in a market that was dominated by products which showed wide variations. There was a need for a legally binding warranty which would ensure that the packed seeds were actually of the named variety on the label of the product. ${ }^{3}$ Hence, the first type of plant protection legislation - plant patents - enabled the carrying out of quality tests that certified the precise characteristics of a seed under a specific name which was recorded in an official seed register..$^{10}$ The patent defined the technological territory of an invention and, therefore, formed the basis of determining infringement, so enabling the inventor to demand compensation for the use of their invention. ${ }^{11}$ Under patent law, an applicant was and still is expected to supply a detailed description of the invention which is being claimed as novel. The inventor is required to disclose the description of the invention so that others skilled in the art may replicate the invention, thus ensuring that knowledge is socially diffused.

In 1953, countries agreed to the International Code of Nomenclature of Cultivated Plants which detailed the definition of plant varieties and norms for granting varietal names. This agreement created a technical space for the granting of rights for varieties as it identified the fundamental differences that occur within species. ${ }^{12}$ Based on this agreement, the International Union for the Protection of New Varieties of Plants (UPOV) Convention developed the sui generis system in 1963 which enabled protection of new plant varieties. This form of varietal protection was referred to as 'plant breeders' rights'. The greatest contribution of the PBRs was that they enabled the breeders to have the right to earn royalties by allowing other parties to use their reproduced seed. This early Convention was, however, confined to acts done for the purpose of trade and provided for farmers' and breeders' privilege. The farmers' privilege allowed for farmers to reproduce any genetic materials for non-commercial use without requiring permission or payment from the right holder. Breeders' privilege allowed the uncompensated use of a protected variety as parent material in the breeding of new varieties.

The UPOV Convention regulations merely played the role of harmonising and rationalising seed certification schemes across countries which chose to be part of UPOV. However, the Convention's reach was limited because it only appealed to industrialising countries, as these were involved in seed development. The Convention was reviewed in 1972, 1978 and 1991 with the aim of further strengthening plant variety protection as a way of attracting more countries. Continuous amendment has resulted in the gradual erosion of residual rights. For instance, UPOV 1991 extended protection to all species, unlike the 1978 Convention which allowed member countries to designate which species or genera they wanted to include for protection. In 1991, the breeder exemption was adjusted to exclude varieties which show minor differences from original varieties, i.e. essentially derived varieties. ${ }^{5}$ The same amendment made the use of saved seed for non-commercial utilisation a flexible requirement that is adjusted by the legislating state or country. ${ }^{11}$

South Africa acceded to the UPOV Convention in $1978^{13}$, which was followed by the amendment of the South African Plant Breeders' Rights Act. One of the most important changes was the extension in the time for PBR protection from 15-20 to 20-25 years. In general, the strengthening of plant variety protection has had a positive impact on South Africa's agricultural sector. For a country that was trying to change historical trends of heavy state dependence in the area of research and development (R\&D) funding, the PBRs did well in providing an avenue for revenue collection which enabled research organisations to generate income that funds their research activities. The income earned from royalties and IPRs during 2000 was reported to make up $10.3 \%$ of the total R\&D expenditure of the national parastatal - the Agricultural Research Council. ${ }^{14}$ This amount increased to $12 \%$ in $2012 .{ }^{15}$ However, the share of royalties is largely the result of the decreasing amount of funding which the organisation is receiving, therefore the trend of revenue collected (after adjusting to inflation) may be described as stagnated.

\section{Research methods and data}

Not much literature exists on the impact of IPRs on plants in developing countries, as compared with the developed countries. This type of analysis has not been carried out in many of these countries because of inefficient time series data being available owing to the later stage at which developing countries joined the UPOV Convention. ${ }^{12}$ Studies that have analysed changes in plant variety protection in developed countries include those done by Diez ${ }^{16}$, Srinivasan ${ }^{17}$ and Pardey et al. ${ }^{4}$ These studies have analysed the trends and changes in plant variety protection policies; the effects of IPRs on plant breeding investment; production of new varieties; and market power or concentration, as well as varietal concentration ratios. Louwaars et al. ${ }^{18}$ and Tripp et al. ${ }^{12}$ conducted extensive studies on IPRs in five developing countries: China, Colombia, Kenya, Uganda and India. The two studies analysed similarities and differences in the individual countries' evolution of plant variety protection policies; enforcement and costs of plant variety protection; production of new varieties; and market competition. A study by Nhemachena et al. ${ }^{1}$ in South Africa focused on assessing the sources of IPRs and determining their impact on plant protection variety registration.

This study focuses on the sources of IPRs as a way to show how PBR legislation has influenced the development and use of locally bred and imported varieties. This is done by assessing adoption trends and varietal concentration ratios. An analysis of the shifts in production areas is also done to show how the strengthened legislation has managed to have a positive effect which seeps down to farm production level through improvements in resource utilisation. An assessment of export market distribution is included to show how institutional strengthening has gone further to affect the country's export market by improving market penetration and competitiveness.

The PBR analysis undertaken in this study uses secondary data recorded between 1950 and 2014. Data on the cultivar adoption were collected from deciduous fruit tree censuses published in the annual reports of deciduous fruit producer organisations. Production distribution per cultivar was measured per tree during the 1950-1976 period and per hectare thereafter. This difference in the form of data is not expected to affect the results of this analysis as cultivar adoption was measured as a percentage of the total production area's statistics. Information on the origins of the cultivars was gathered from deciduous fruit cultivar registries, research bulletins and annual research reviews. Data on export volumes and market distribution were collected from the annual reports of deciduous fruit producer organisations.

\section{Results and discussion}

\section{Changes in dessert peach and nectarine production}

\section{Production area}

Figure 1 shows that the distribution of nectarine and dessert peach production has significantly changed over the years. In 1950, all dessert peach and nectarine production occurred in an area classified as the High Chilling Units (CU) Zone as it provides over $800 \mathrm{~h}$ of temperatures below $7^{\circ} \mathrm{C}$ in a production season. These conditions were provided in the Groenland, Franschhoek and Ceres production regions. Figure 1 shows that in $1950,55 \%$ of the production was concentrated in these three regions. However, by 1980, the percentage production area of these three regions had reduced to $30 \%$ while Piketberg, a production region which provides $466.5 \mathrm{CU}$ and is classified in the Medium CU Zone, became the main area for peach and nectarine production. There was no significant change in the production district distribution in the 1990s. However, after 2000, the Little Karoo production district - which provides $359-530 \mathrm{CU}$ and is classified in the Low CU Zone - became the fastest growing production district as its share in total production area increased from $5.5 \%$ to $40 \%$ of the total production area between 2000 and 2012. The level of concentration of production has also increased with time as the area planted to other minor production regions has diminished over time. 


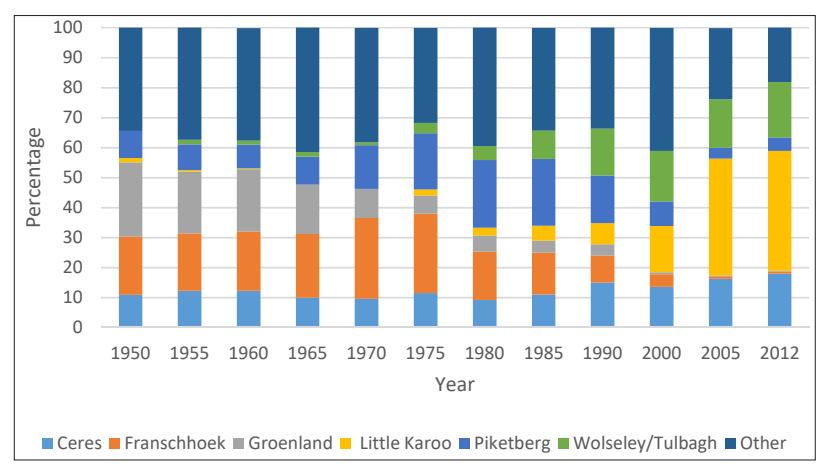

Figure 1: Trend in regional distribution of peach production in South Africa, 1950-2012.

\section{Cultivars used in production}

The shift to warmer production areas was made possible by the use of cultivars which were adapted to warmer winter temperatures. Farmers also made use of dormancy-breaking chemicals which would enable the trees to progress to fruit-bearing stage without the provision of low, dormancy-breaking winter temperatures. The critical role that cultivar choice serves in this transition is shown in the narrow selection of cultivars. As shown in Figure 2, the industry continued to use the South African (RSA)-bred Early Dawn cultivar. However, it utilised increasing percentages of the UK-bred Peregrine and Duke of York cultivars and the US-bred Flamekist, Armking, Independence and Springcrest cultivars during this transition. As shown in Figure 2, the production share of locally bred cultivars decreased from $51 \%$ to 44\% between 1950 and 1973 as a result of the increase in adoption of the UK-bred cultivars. As the use of the UK-bred varieties aided in overcoming the climatic limitation, their share in production rose from $32 \%$ to $55 \%$ between 1952 and 1967 . Nevertheless, the influence of the UK-bred cultivars was limited owing to their limitations in pest resistance. Consequently, the adoption of RSA-bred cultivars rose to $73 \%$ in the early 1980 s through the adoption of a new group of cultivars (Rhodes and Van Riebeeck) which had been bred to withstand higher temperatures and provide high pest tolerance, which was an essential quality attribute in cultivar selection for local farmers. Here the PBR legislation was instrumental in facilitating the availability of a wide variety of good-quality germplasm that the local breeders could utilise.

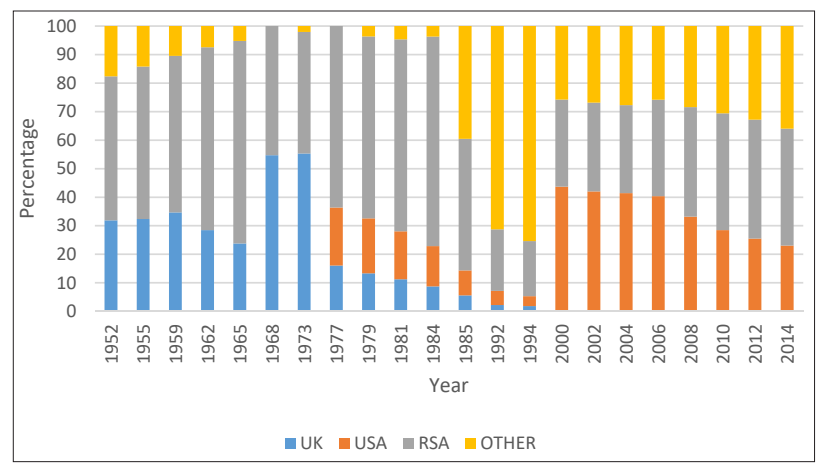

Figure 2: Share of area planted to different nectarine and dessert peach varieties classified according to genetic origin, 1952-2014.

The 1990s constituted a period which was characterised by market deregularisation and trade liberalisation. These changing market conditions created a demand for the adoption of many different, new cultivars ${ }^{19}$; particularly US-bred cultivars, as their share in production area increased from $4 \%$ in 1994 to $44 \%$ in 2000. Prior to 1990, the US-bred cultivars had struggled to acquire market share in South Africa, being planted to a maximum production share of $19 \%$ in 1979 as shown in Figure 2. However, with the easier importation of production inputs which resulted from better trade relations, South African farmers realised that they could viably utilise the US-bred cultivars. The US-bred cultivars were especially popular because they had lower labour cost implications as a result of their dwarf tree structures which required less pruning and trellising. The introduction of modified production practices tailored to the new cultivars facilitated the improved utilisation of land, as these allowed for highdensity plantings of between 1667 and 3333 tree/ha. ${ }^{20}$ These densities were much higher than the 600 trees/ha that was the industry average before 1970. The RSA-bred cultivars that were adopted after 1994 met these high-density planting requirements, hence their continual use after 2000, as shown.

\section{Varietal development and concentration ratios}

As outlined in the section above, the significance of the Plant Breeders Rights Act's impact gradually shifted over time from that of providing cultivars planted in the field to that of providing cultivars mainly used as germplasm for breeding. This shift is especially true for nectarine cultivar development, which was a direct result of the variety exchange policies as all parent material was externally sourced, unlike the case of dessert peaches in which local wild varieties (landraces) were frequently used. Table 1 shows that South Africa experienced an increase in the rate of cultivar development between 1965 and 2014. The most significant was recorded in the last two decades, in which 21 cultivars were developed between 2005 and 2014, while 9 cultivars were bred during the 1985-1994 period. The influence of PBR policy on the Agricultural Research Council's productivity was also enabled by the availability of advanced breeding technology and the adoption of modern breeding techniques. Of much influence was the change in the national research funding policy, which gradually shifted towards funding individual projects based on the success of the adoption of their research output. The competitive way in which research funds are allocated ${ }^{21}$ has resulted in reductions in funding of other activities, such as soil research, as well as in similar breeding projects which rely on the same funding sources ${ }^{22}$.

Table 1: Number of dessert peaches and nectarines bred in South Africa, 1965-2014

\begin{tabular}{c|c|c|c}
\hline \hline Years & Dessert peaches & Nectarines & Total \\
\hline $1965-1974$ & 1 & - & 1 \\
\hline $1975-1984$ & 2 & 1 & 3 \\
\hline $1985-1994$ & 4 & 2 & 6 \\
\hline $1995-2004$ & 4 & 5 & 9 \\
\hline $2005-2014$ & 4 & 17 & 21 \\
\hline
\end{tabular}

As a consequence of success in local breeding, the fresh fruit sector utilises an increasing number of varieties, as shown in Figure 3. As illustrated, the area planted to one variety has decreased (shown by the negatively sloped graphs). The gradients of the graphs' slopes increase with an increase in the number of cultivars, indicating that cultivar concentration has shifted from the Top 1 cultivar to the Top 5 cultivars. This shift indicates a general improvement in the quality of cultivars, as the difference in production share between the shares of the Top 1 and Top 5 category has reduced. As shown in Figure 3, the percentage area shares planted to the Top 1 and Top 5 cultivars were $31 \%$ and $81 \%$ in 1952, respectively, while the area shares planted to the Top 1 and Top 5 cultivars were $9 \%$ and $28 \%$ in 2014 , respectively. Improvement in cultivar quality is further highlighted by the fact that the concentration levels of the Top 1 cultivar in 1952 are comparable with those of the Top 5 cultivars in 2014. Lower varietal concentration is advantageous to the sector, as it implies that the production risk is spread. That is to say, if the yield of one cultivar were to be negatively affected by, for example, a newly discovered disease, farmers would have the option to switch to alternative cultivars that perform on par with the affected cultivar. Lower varietal concentration also has enabled better fruit handling, as the harvest season is spread over a longer period. Staggered harvests have had positive implications for improving fruit quality and reducing post-harvest losses. 


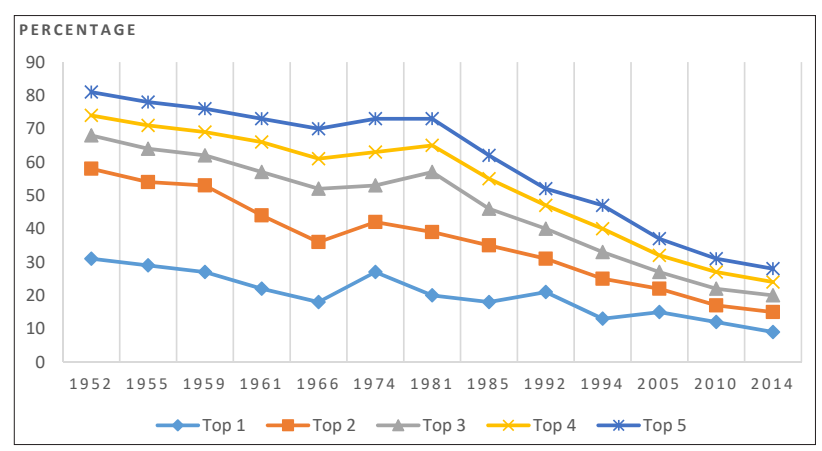

Figure 3: Varietal concentration of nectarine and dessert peach cultivars in South Africa, 1952-2014.

One of the limitations of the tree census data used in this section is that the data for cultivars which had small shares of the production are clustered. This clustering introduces some ambiguity as to the effect of the Plant Breeders' Rights Act, especially in a case in which a significant portion of the area is reported as 'other varieties', as shown during 1992 and 1994. In order to uncover more detail, this PBR analysis is extended in the next section to investigate the impact of legislation on exports. Here, the details on cultivar origins are recorded with less aggregation.

\section{Changes in dessert peach and nectarine exports}

Fruit firmness is the main characteristic used to determine whether a cultivar can be used for export. An export regimen typically endures 3-4-week voyages by sea ${ }^{23}$; therefore, cultivars are required to have some level of firmness at harvest for them to withstand harsh transportation conditions which can cause reductions in fruit quality and shelf life. Through the use of the PBR legislation, varieties which better meet these needs have been introduced and as a result, the proportion of annual peach and nectarine production that is exported as fresh fruit increased from 1.8\% to 6\% between 1949 and 2012. ${ }^{22}$

Because of this critical prerequisite, there is a difference in export cultivar composition from that which is reported at production level. To provide a detailed analysis, dessert peach exports will be analysed separately from nectarine exports.

\section{Changes in dessert peach cultivars use}

Figure 4 shows the trends in cultivar use for dessert peach exports, classified according to the country of origin. As shown in Figure 4, South African dessert peach exports were mostly made up of UK-bred cultivars (Peregrine and Duke of York) and RSA-bred cultivars (Early Dawn, Inkoos and Marina) between 1950 and 1957. The UK-bred cultivars had higher export volumes, as their share in peach export volumes increased from $50 \%$ to $70 \%$. With time, the industry began to realise that this concentrated cultivar use limited the industry's growth as the export of Peregrine and Early Dawn produced two distinct supply peaks during week 47 and week 1, respectively, which depressed prices to uneconomic levels. As a result, there was the need to introduce more cultivars that would stagger the fruit deliveries and maintain sustainable market prices. To rectify the situation, three more RSA cultivars Rhodes, Culemborg and Van Riebeeck - were introduced, resulting in an increase in the RSA-bred cultivars' share in export volume percentage to $82 \%$ in 1990 .

The most significant change in cultivar use patterns in the history of the sector was experienced after 1990 when agricultural market and political reforms led to the opening up of the country to new international markets. Thus, factors relating to international demand, as opposed to local sustainable production, began to play a greater role in cultivar selection. Consequently, US-bred cultivar share in exports increased from 16\% to 32\% between 1990 and 2014 owing to the large demandpull effect of the export market. These cultivars were in line with the new consumer preference that had drifted towards a particular type of peach cultivar which was defined by its bright colour, sweet taste and preferred fruit size range. ${ }^{24,25}$ According to Janick ${ }^{26}$, importers also preferred these cultivars because they handled better, showed fewer bruises, and were less prone to diseases like brown-rot, which causes high post-harvest losses. Worth noting, is the continual presence of locally bred varieties which remained competitive in exports until 2014.

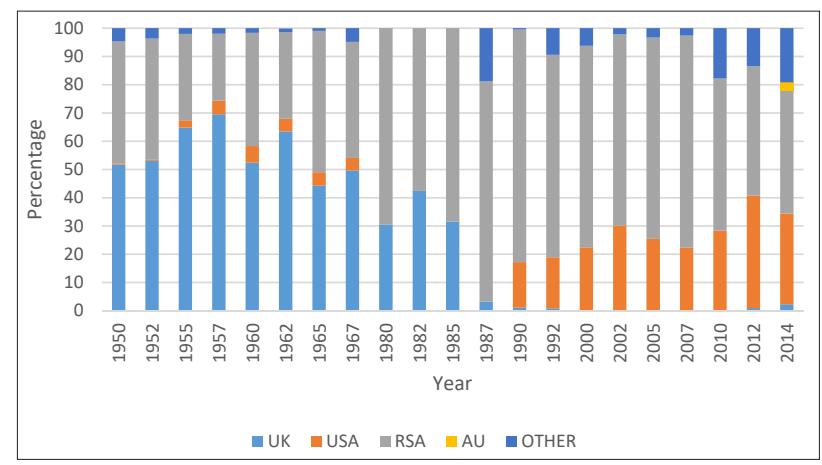

Figure 4: Changing distribution of nectarine and dessert peach export varieties by country origin, 1950-2014.

\section{Changes in nectarine cultivars used for exports}

Differently from dessert peaches, South African exporters relied solely on imported nectarine cultivars from 1950 to 1986, as shown in Figure 5. From 1950 to 1966, only two cultivars met the export conditions of the industry. The New Zealand bred cultivar, Goldmine, constituted between $82 \%$ and $100 \%$ of the export volumes, while the UK-bred cultivar, Early River, made up the remainder. Census figures show that the Goldmine variety's performance on the market fell severely, as its export cartons reduced from 28456 cartons to 5763 cartons between 1950 and 1957. However, as there was no alternative, this cultivar remained the main export cultivar. With the use of PBR legislation, the country was able to start using US-bred varieties - May Glo, Fantasia and Flavortop - after 1980. As shown in Figure 5, US-bred cultivars dominated the market by 1982 , when $69 \%$ of the export volumes comprised US-bred varieties.

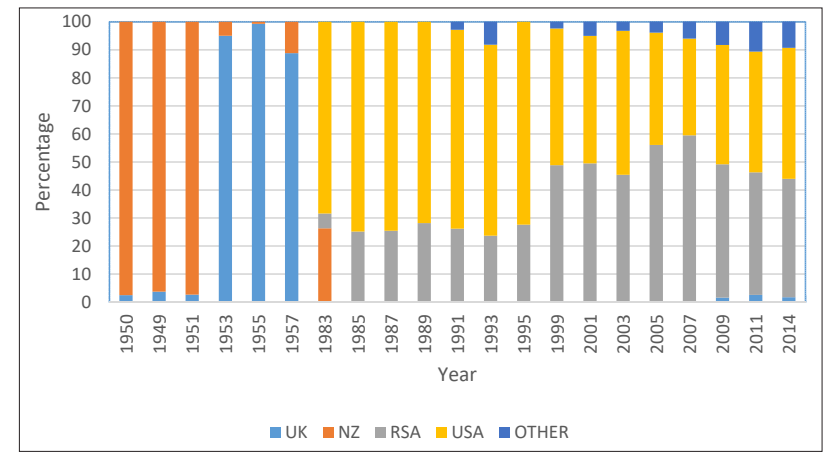

Figure 5: Changing distribution of nectarine export varieties by country origin, 1950-2014.

US-bred cultivars dominated export volumes until the 1990s. By 2000, the RSA-bred cultivars had gained ground and, in 2014, their export volume share was $40 \%$. Other factors which drive their export use, in addition to high supply from local production adaptability, are: increasing consumer health awareness ${ }^{27}$, consumers' lack of loyalty to a specific cultivar, and the availability of new markets. Taking advantage of the institutional environment, exporters used a total of 167 cultivars in 2014. This use was a huge increase from the two cultivars which were used in 1966. The availability of a diverse number of cultivars has allowed exporters to implement an innovative marketing strategy which makes use of harvest dates, as opposed to volumes, as was done in the 1950s. Through the delivery of fruit harvested earlier and later in the season, the country has taken advantage of the high off-season prices and obtains premiums that range between $50 \%$ and $100 \% .{ }^{28}$ This has become the source of South Africa's competitive advantage against its biggest competitor Chile - which has its competitive advantage based on volumes. 


\section{Changes in export destinations}

South African nectarine and dessert peach exports were mainly targeted towards supplying the UK market for the first part of the 1950s, as shown in Table 2. Volumes destined for the UK decreased from $63 \%$ to 29\% between 1970 and 1975 as a result of export bans issued against South Africa during that time. As shown, the percentage of export volumes delivered to the alternative market, Europe, increased from $26 \%$ to $98 \%$ between 1970 and 1980 . After 1990, the export restrictions were removed, and South Africa began to enjoy a wider export distribution, as shown by the larger diversity in export markets. The weakening demand in Europe played a part in the expansion towards the Middle Eastern and Asian markets, which showed strong growth potential. ${ }^{27} \mathrm{~A}$ critical factor motivating this shift is the latter markets' less stringent non-tariff measures (ethical; sanitary and phytosanitary; and technical barriers to trade) when compared with the European Union. ${ }^{29}$ The two largest export destinations classified under 'other' in 2012 were the United Arab Emirates and Mauritius - constituting 16\% and 5\% of export volumes, respectively.

Table 2: Distribution of dessert peaches and nectarines on global market (percentages)

\begin{tabular}{c|c|c|c|c}
\hline \hline Year & UK & Europe & USA & Other \\
\hline 1950 & 97 & 3 & 0 & 0 \\
\hline 1955 & 72 & 28 & 0 & 0 \\
\hline 1960 & 63 & 24 & 1 & 12 \\
\hline 1965 & 65 & 19 & 0 & 16 \\
\hline 1970 & 63 & 26 & 1 & 10 \\
\hline 1975 & 29 & 65 & 3 & 3 \\
\hline 1980 & 0 & 98 & 0 & 2 \\
\hline 1985 & 0 & 97 & 0 & 3 \\
\hline 1990 & 50 & 48 & 0 & 2 \\
\hline 1995 & 40 & 42 & 0 & 18 \\
\hline 2000 & 32 & 38 & 0 & 30 \\
\hline 2005 & 52 & 22 & 0 & 36 \\
\hline 2010 & 47 & 16 & 0 & 37 \\
\hline 2014 & 49 & 21 & 0.5 & 29.5 \\
\hline
\end{tabular}

\section{Summary and conclusion}

The evolution of PBRs through the UPOV Convention from 1961 through to 1991 has positively affected the South African fresh peach and nectarine sector. The study has shown that the incentive that has been provided by PBRs has interacted with several factors such as deregularisation, international trade policies, market trends, adoption of non-variety technologies and research intensity. The combined effect of these factors led to the growth and development of the peach and nectarine fresh fruit sector. This study did not try to separate attribution between these different factors, but rather highlighted the critical facilitative role that the PBR legislation has played in contributing to the sector's growth.

During the early years after the introduction of the PBR legislation, the protection of plant variety served as a vehicle which enhanced the use of foreign-bred cultivars within South Africa. The importance of PBR legislation was shown by the widespread adoption of foreignbred cultivars at production stage and their wide use for exports. These were instrumental in facilitating the penetration of export markets and encouraging the growth of export volumes. The use of these import varieties also facilitated peach and nectarine production in areas which were once deemed unsuitable. The paper also highlighted a phase in the 1950s which testifies to how growth in exports can be halted by the lack of genetic diversity. During a later period, the role of PBR evolved to that of stimulating the development of locally bred varieties. The rate of cultivar development by local breeders more than doubled between the periods 1995-2004 and 2005-2014. The market share of locally bred cultivars has seen an increasing trend owing to the cultivars' good qualities. The wider availability and accessibility of better adapted cultivars has resulted in spreading production risk and higher remuneration across export markets.

The PBR legislation has provided a way for the local agricultural research parastatal to generate additional funds to finance its research projects. In $2014,12 \%$ of the funding of the national agricultural research institution was acquired through royalties. Although the percentage of royalties from total research funding shows an increasing trend, the amount collected remains insufficient to meet all the funding needs of the institution. Encouraging growth in royalties collected by the Agricultural Research Council would require strengthening varietal legislation through widening PBR legislation's scope of protection and improving enforcement. However, the feasibility of such an amendment is constrained by the limited state administrative resources. Such a change is also likely to have negative welfare effects on local breeders and poor farmers as it will result in the reduction of the residual rights which are available at present. Focusing on raising funds through royalties will most likely cause an overemphasis on the need to address the research needs of commercial farmers who have the finances to purchase improved cultivars. Research resources will also be devoted to developing cash crop seeds instead of other crops (e.g. indigenous crops and unexplored crops such as rice) which may become more lucrative if given adequate research support. Therefore, policymakers are encouraged to carefully consider the mixed effects of such changes in legislation if they are to be implemented.

The study has shown that locally bred cultivars have made significant contributions to increasing resource (land) utilisation, export revenues and market penetration. As benefits are high, this provides a motivation for an increase in R\&D funding to the local breeding organisation, the Agricultural Research Council. Civil society and agribusinesses share the benefits of research investments, therefore both government and the private sector should be equally motivated to support local breeding. The provision of private and public research funding would be a more viable way to secure finances for agricultural research, as the measures that would be required to increase royalty collection may not be feasible.

\section{Acknowledgements}

This work was supported by the Agricultural Research Council's Professional Development Programme and the University of Pretoria's Department of Agricultural Economics, Extension and Rural Development. This paper would not have been successfully written without the insightful thoughts of Professor Johann Kirsten, Dr Frikkie Liebenberg and Mrs Manana Rancho Mamabolo. Their contributions to earlier versions of this paper are sincerely appreciated. I also thank the anonymous reviewers for their constructive comments that further improved the paper.

\section{References}

1. Nhemachena CR, Liebenberg FG, Kirsten J. The evolving landscape of plant breeders' rights regarding wheat varieties in South Africa. S Afr J Sci. 2016;112(3/4), Art. \#2015-0164, 8 pages. http://dx.doi.org/10.17159/ sajs.2016/20150164.

2. Eaton D, Tripp R, Louwaars N. The effects of strengthened IPR regimes on the plant breeding sector in developing countries. Paper presented at: International Agricultural Economist Conference; 2006 August 12-18; Gold Coast, Australia.

3. Rangnekar D. Intellectual property rights and agriculture: An analysis of the economic impact of plant breeders rights. London: Action Aid; 2000.

4. Pardey PG, Koo B, Drew J, Horwich J, Nottenburg C. The evolving landscape of plant varietal rights in the United States, 1930-2008. Nat Biotechnol. 2013;31(1):25-29. http://dx.doi.org/10.1038/nbt.2467. 
5. Salazar R, Louwaars N. Protecting farmers' new varieties: Approaches to rights on collective innovations in plant resources. World Dev. 2007;35(9):15151528. http://dx.doi.org/10.1016/j.worlddev.2006.05.019.

6. Sahai S. India's plant variety protection and Farmers' Rights Act, 2001. Curr Sci India. 2003;84(3):407-412.

7. Kent L. 'What's the holdup? Addressing constraints to the use of plant biotechnology in developing countries'. AgBioForum. 2004;12(7):1-2.

8. Alston JM, Venner RJ. The effects of the US Plant Variety Protection Act on wheat genetic improvement. Res Policy. 2002;31:527-542. http://dx.doi. org/10.1016/S0048-7333(01)00123-8.

9. Sansavini S, Gamberini A, Bassi D. Peach breeding, genetics and new cultivar trends. Acta Hortic. 2006;713(1):23-48. http://dx.doi.org/10.17660/ ActaHortic.2006.713.1

10. Claus $P$, Thiele-Witting M. Plant variety protection - a fascinating subject. World Patent Inform. 2003;25:243-250. http://dx.doi.org/10.1016/S01722190(03)00074-7

11. Rangnekar D. Technology paradigms and the innovation - Appropriation interface: An examination of the nature and scope of Plant Breeders' Rights. Promotheus. 2008;17(2):125-138.

12. Tripp R, Louwaars N, Eaton D. 2007. Plant variety protection in developing countries. A report from the field. Food Policy. 2007;32:354-371. http:// dx.doi.org/10.1016/j.foodpol.2006.09.003

13. Moephuli SR, Moselakgomo MA, Phehane V. The Agricultural Research Council's role in plant variety protection and technology transfer - Promoting publicly funded research. UPOV Workshop; 2012 March 05; Zanzibar, Tanzania.

14. Liebenberg F, Kirsten J. South Africa: Coping with structural changes. In: Pardey P, Julian M, Alston N, Piggott R. Agricultural R\&D in the developing world: Too little too late? Washington D.C.: International Food Policy Research Institute; 2006

15. Agricultural Research Council (ARC). Annual report. Pretoria: Government Printers; 2012.

16. Diez MCF. The impact of plant varieties rights on research: The case of Spain. Food Policy. 2002;27:171-183. http://dx.doi.org/10.1016/S03069192(02)00010-6

17. Srinivasan CS. Concentration in ownership of plant variety rights: Some implications for developing countries. Food Policy. 2003;28:519-546. http:// dx.doi.org/10.1016/j.foodpol.2003.10.003
18. Louwaars N, Dons H, Van Overwalle G, Raven H, Arundel A, Eaton D, et al. Breeding business: The future of plant breeding in the light of developments in patent rights and plant breeders' rights. CGN report no. 2009-14. Wageningen: Centre for Genetic Resources, Wageningen University; 2009.

19. Vink N. South African agriculture in the 1970s. S Afr J Econ Hist. 1999;14(1):90-113.

20. Cook NC. An overview of plum training systems in South Africa. Acta Hortic. 2004:732:435-438.

21. Liebenberg F, Pardey P, Kahn M. South African agricultural research and development: A century of change. InStePP Paper 10-01. Staff Paper Series. 2010. Available from: http://ageconsearch.umn.edu/record/56688/files/p1001.pdf

22. Tsvakirai CZ. An economic evaluation of South Africa's peach and nectarine research [dissertation]. Pretoria: University of Pretoria; 2015.

23. Pieterse WM, Smith WJC, Lotz E. Advances in peach and nectarine breeding at the Agricultural Research Council of South Africa. Acta Hortic. 2012;962(7):75-80. http://dx.doi.org/10.17660/ActaHortic.2012.962.9

24. Giovannini D, Liverani A, Merli M, Brandi F. Breeding strategies to improve peach fruit quality. Acta Hortic. 2006;713(12):107-112. http://dx.doi. org/10.17660/ActaHortic.2006.713.12

25. Huysamer M. Integrated cultivar, rootstock and environment in the exportdriven South African deciduous fruit industry. Acta Hortic. 1997:451(91):755760. http://dx.doi.org/10.17660/ActaHortic.1997.451.91

26. Janick J. Origin of dissemination of Prunus crops: Peach, cherry, apricot, plum, almond. Leuven: International Society for Horticultural Science; 2011.

27. Pickelsimer C. Republic of South Africa fresh deciduous fruit semi-annual: USDA Foreign Agricultural Service. Global Agricultural Information Network report. c2014 [cited 2017 Jan. 17]. Available from http://gain.fas.usda.gov/ Recent\%20GAIN\%20Publications/Fresh\%20Deciduous\%20Fruit\%20Semiannual_Pretoria_South\%20Africa\%20-\%20Republic\%20of_5-14-2014.pdf

28. Deciduous Fruit Board (DFB). Consumer Advisory Committee reports: Memorandum. Paarl: DFB; 1994.

29. Dodd M, Cronje P, Taylor M, Huysamer M, Kruger F, Lotz E, et al. A review of the post-harvest handling of fruits in South Africa over the past twenty five years. S Afr J Plant Soil. 2010;27(1):97-116. https://doi.org/10.1080/0257 1862.2010.10639974 